\title{
The impact of social capital on the operation of non-profit sports clubs
}

\author{
She Tao \\ (Sichuan University of Arts and Science, sichuan dazhou 635000)
}

\begin{abstract}
The nonprofit sports clubs fill the gaps in the field of community sports in China. This paper mainly discusses the impacts of the social capital on the operation of non-profit sports clubs and proposes a research model for the impacts according to the formation mechanism of social capital. The research selects eight nonprofit sports clubs in Sichuan province as objects of study, calculates their composite scores in social capital with the vertical linkages, horizontal linkages and social linkages as measurable indicators, and analyzes the influence of social capital on the ability of capital gains and the continued viability of sports clubs by multiple linear regression models. The results show that without considering the market competition, the vertical linkages, the main channel of the sports club social capital formed and accumulated, have the highest contribution to the social capital following the social linkages and then horizontal linkages. Accumulation of social capital will significantly impact the funding sources and the sustainable management of clubs, so nonprofit sports clubs are recommended to strengthen communication with the competent authorities and fight for more financial support and a favorable business environment.
\end{abstract}

Keywords-Social capital, Sports clubs, Non-profit organization, Operation of clubs

\section{INTRODUCTION}

Accompanied China's rapid economic development, the operating environment of the nonprofit sports clubs is changed by the developing requirement of sports for all, and they need more space for development and continued viability. From the history of the development of our nonprofit sports clubs, early nonprofit sports clubs are loosely organized by the sports organizations of the grassroots masses, of which mainly members are sports-minded grassroots. The club's management and organization level are low. The National Youth Sports Club established in 1999 is the most representative nonprofit sports clubs. The number of nonprofit sports clubs growing geometrically in the latest decade. According to incomplete statistics, the number of nonprofit sports clubs in Sichuan Province is four times more than ten year ago and now there are about 1283 nonprofit sports clubs operating. The growth trend of the number of nonprofit sports clubs in Sichuan Province from 2002 to 2012 are shown in Figure 1

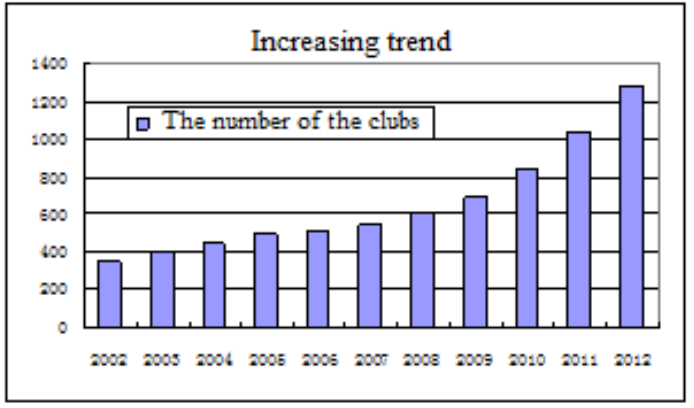

Figure 1 the number of nonprofit sports clubs in Sichuan Province

As can be seen from the figure, influenced by Beijing Olympic Games and the Guangzhou National Games and other major sporting events in China, a number of nonprofit sports clubs have been established in Sichuan Province since 2008. Limited by policy restrictions and funding system, the funds channels for operation affect the continued viability of the clubs. Part of the research results show that the social capital of organizations will affect the scale of the organizations to obtain government funding. Therefore, to the large number of nonprofit sports clubs, social capital will affect the capital gains and the continued viability. The study mainly studies the impact of social capital on the operation of non-profit organization from impact of capital gains and the continued viability.

\section{II.MEASUREMENT OF SOCIAL CAPITAL OF NONPROFIT SPORTS CLUBS}

Social capital of non-profit organization mainly indicates the ability of non-profit organizations getting scarce resources through vertical linkages, horizontal linkages and social linkages. The amount of social capital of the organization the size of depends on the organization's external environmental factors and entrepreneurial initiative. Social capital will help the organization to get more government funding or policy support, and enhance the sustainable viability and economic benefits of the organization especially the non-profit organizations rely on government funding and social funds. Wang Shuang and Du Bing points out in the literature [3] that social capital will affect the development of nonprofit sports clubs and broad social relations of person in charge of the club enable the club to get more financial support and enhance the club's sustainable management. The organization's social 
capital is high complex and difficult to be measured. Sun Junhua and Chen Chuanming etc point out in the literature [4] that the measurement indexes of social capital are difficult to selected and the interpreting scope of variables for social capital are limited. Shi Junwei, Hu Lijun and Fu Haiyan etc indicate in literature [5] that social capital will enhance the organizations' competitive advantage, mainly because the vertical social capital can help organizations access to priceless project information and more scarce resources. In this paper, the proportion of government funding, work experience background, and social interaction breadth of managers are uses as measuring indexes of social capital of nonprofit sports clubs to calculate the composite score of social capital.

This study selects eight nonprofit sports clubs in Sichuan Province as objects of study, annual amount of subsidy from government as the value of the variable measuring the vertical linkages, the number of enterprises and institutions the first responsible person of the club once worked as the value of the variable measuring the horizontal linkages, and the breadth of the social scope of the club as the value of the variable measuring the social linkages. Social capital measurement and the analyzing results obtained by the application of factor analysis are shown in Table 2-1.

TABLE 1 SOCIAL CAPITAL MEASUREMENT AND THE ANALYSIS

\begin{tabular}{cccc}
\hline Factor & $\begin{array}{c}\text { Factor loading } \\
\text { values }\end{array}$ & \multicolumn{1}{c}{ Value of $\mathbf{p}$} & R-squared \\
\hline vertical linkages & 0.891 & 0.0158 & 0.31 \\
horizontal linkages 0.714 & 0.0498 & 0.12 \\
social linkages & 0.618 & 0.0479 & 0.09 \\
\hline
\end{tabular}

As can be seen from Table $2-1,52 \%$ of the social capital can be explained by indicator variables calculated by the value of $\mathrm{R}^{2}$, which indicate that the indicators selected are proper. In addition, the club's social capital indicators selected for the clubs in factor analysis process are validated by $5 \%$ significance test selected, which means the regression results of indicator variables are reliable.

From Table 1 it can be inferred that there are a little difference among the loading values of each factor and the vertical linkage is the main source of social capital accumulating and developing. The loading values of three factors are relatively large which means all the three factors cannot be neglected. Social capital is calculated as follows

$$
Y=0.891 y_{1}+0.714 y_{2}+0.618 y_{3}
$$

First the composite score of the object' social capital is calculated according to formula 2.1, and then the impacts of social capital on continued viability and economic benefits of nonprofit sports clubs are analyzed.

\section{THE IMPACTS OF SOCIAL CAPITAL ON THE OPERATION OF NONPROFIT SPORTS CLUBS}

\section{a) Data Source}

This paper selects eight nonprofit sports clubs in Sichuan Province as objects of study and the operation data and financial data of the objects from 2008 to 2012 as data source to study the impacts of social capital on continued viability and economic benefits of nonprofit sports clubs.

\section{b) The object variables}

In this paper, cash flow $\mathrm{x}_{1}$, total assets $\mathrm{x}_{2}$ and solvency $x_{3}$ etc of the objects are chosen as independent variables, and the composite score $\mathrm{y}$ of social capital is chosen as the dependent variable. Here we study the impacts of social capital on the operation of nonprofit sports clubs from an organizational perspective.

\section{c) Mathematical model}

The paper adopts multiple linear regression models to analyze the impacts of social capital on the operation of nonprofit sports clubs and test the explaining extent of regression item to the dependent variables. The formula of the model is shown as (3.1):

$$
\mathrm{y}=\beta x+u \quad i=1,2, \ldots, N
$$

$\mathrm{N}$ represents the number of object clubs, dependent variable $y$ indicates the composite score of social capital, $\mathrm{x}$ is independent variable, $\beta$ is the independent variable coefficient and $\mu$ is the random disturbance term. The matrix form of the model is as follows

$$
\left(\begin{array}{c}
\mathrm{y}_{1} \\
y_{2} \\
\vdots \\
y_{N}
\end{array}\right)=\left(\begin{array}{cccc}
x_{1} & 0 & \cdots & 0 \\
0 & x_{2} & \ddots & \vdots \\
\vdots & \ddots & \ddots & 0 \\
0 & \cdots & 0 & x_{N}
\end{array}\right)\left(\begin{array}{c}
\beta_{1} \\
\beta_{2} \\
\vdots \\
\beta_{N}
\end{array}\right)+\left(\begin{array}{c}
\mu_{1} \\
\mu_{2} \\
\vdots \\
\mu_{N}
\end{array}\right)
$$

$\mathrm{Y}$ is the $\mathrm{N}$-dimensional column vector of observed value of dependent variable, $\mathrm{X}$ is a $\mathrm{N} \times(\mathrm{K}+1)$ matrix composed by of observed value of $\mathrm{N}$ sample points of all independent variables, $\quad \beta$ is $\mathrm{k}+1$-dimensional coefficient vector and $\mu$ is the $\mathrm{N}$-dimensional column vector of disturbance term.

$$
R S S=\sum_{i=1}^{N} \hat{\mu_{i}^{2}}=(Y-X \beta)^{\prime}(Y-X \beta)
$$

If RSS is described as Q, formula (3.3) can be expressed as

$$
Q=\sum_{i=1}^{N} \hat{\mu_{i}^{2}}=(Y-X \beta)^{\prime}(Y-X \beta)
$$

The formula for regression coefficient is

$$
b=\left(X^{\prime} X\right)^{-1} X^{\prime} Y
$$


The variance of the random disturbance term is calculated as follows:

$$
\hat{\sigma^{2}}=\frac{\sum \hat{\mu_{i}^{2}}}{N-k-1}
$$

In this study, the model uses $\mathrm{F}$ statistic to test the significance, the formula is shown as follows:

$$
F=\frac{\sum_{i=1}^{N}\left(y_{i}-\bar{y}_{i}\right)^{2} / k}{\sum_{i=1}^{N}\left(\hat{y_{i}}-\bar{y}_{i}\right)^{2} /(N-K-1)}
$$

\section{RESULTS ANALYSIS}

\subsection{Description}

TABLE 2 DESCRIPTIVE RESULTS

\begin{tabular}{|c|l|l|l|}
\hline \multicolumn{4}{|c|}{ Dependent Variable: $\mathbf{Y}$} \\
\hline \multicolumn{4}{|c|}{ Included observations: 328} \\
\hline \multicolumn{4}{|c|}{ Convergence achieved after 3 iterations } \\
\hline R-squared & 0.7926 & Mean dependent var & 10.1151 \\
\hline $\begin{array}{c}\text { Adjusted } \\
\text { R-squared }\end{array}$ & 77.1714 & S.D. dependent var & 14.1374 \\
\hline S.E. of regression & 13.7369 & Akaike info criterion & 4.6231 \\
\hline $\begin{array}{c}\text { Sum squared } \\
\text { resid }\end{array}$ & 59.3324 & Schwarz criterion & 5.7116 \\
\hline Log likelihood & -139.0153 & Hannan-Quinn criter. & 4.8213 \\
\hline F-statistic & 1.8739 & Prob(F-statistic) & 0.0213 \\
\hline
\end{tabular}

From Table 4.1 we find that the test values of AIC and SC are 4.6231 and 5.7116. Combining the values of AIC, SC and HQC, we can infer that the model in this paper is validated by Akaike Information Criterion. Schwarz Information Criterion and Hannan-Quinn Information Criterion. Therefore the proposed model is suitable for the analysis of sample data.

The average variance and standard deviation of dependent variable y are 10.1151 and 14.1374 which indicate the impacts of social capital on operation of organization are obvious. The value of $\mathrm{R}^{2}$ is 0.7926 indicating that the interpretable part of regression items to dependent variable is $79 \%$, which means the selection of independent variables is proper and has high reliability, and the results have certain reference value.

\subsection{Analysis of results}

TABLE 3 UNEMPLOYMENT INSURANCE'S INFLUENCE ON THE ENTERPRISE MANAGEMENT (THE FULL TITLE HAS A PROBLEM, AND DON'T)

\begin{tabular}{|l|l|l|l|l|}
\hline \multicolumn{5}{|c|}{ Dependent Variable: $\mathbf{Y}$} \\
\hline \multicolumn{5}{|c|}{ Sample: 1328} \\
\hline Included observations: 328 \\
\hline Variable & Coefficient & Std. Error & t-Statistic & Prob. \\
\hline C & -23.0219 & 1.6086 & 6.7903 & 0.0013 \\
\hline X1 & 7.2689 & 0.5953 & 3.6358 & 0.0114 \\
\hline X2 & 9.2523 & 0.2532 & 0.5525 & 0.0467 \\
\hline X3 & 4.9061 & 0.5156 & 1.9423 & 0.0153 \\
\hline
\end{tabular}

It can be inferred from the Table 4-2 that independent variables $\mathrm{x} 1, \mathrm{x} 2$ and $\mathrm{x} 3$ are validated by $5 \%$ significance test, which means the regression results of indicator variables are reliable. The coefficient of regression item is positive, and the greater the regression coefficient is the greater the regression variables impact on the dependent variable. The results indicate that the social capital has obvious impacts on the continuous operation and benefits of the clubs. The estimated value and actual value of the dependent variable in the model are shown in Figure 2

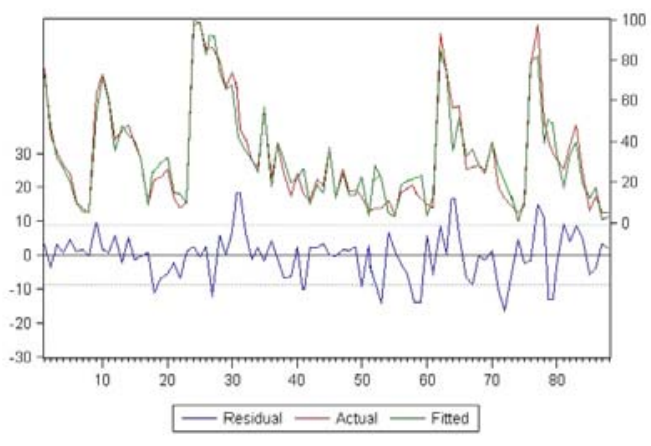

Figure 2 actual value, estimated value and residual of dependent variable

As Figure 2 indicates that the difference between estimated value and actual value of the mode is small which means the results are reliable. Comprehensive analysis of the regression results show that nonprofit sports clubs are not particularly seek for maximize profit, so sustainable management ability is relatively more important. Therefore, the non-profit clubs should pay attention to the following points in the accumulation and use of social capital: First, social capital can bring objective government funding for non-profit clubs. So the managers should focus on communication and coordination with the higher authorities, in order to secure more funding to alleviate the pressure of the club. Second, a wide range of social networking could bring more customers resources and raise funds for the clubs. Therefore, as the role of the business, managers should broaden their own social network, in order to raise funds 
for the club to increase funds channels and avoid operational risk due to the decrease in government funding. Finally, nonprofit sports clubs should strengthen horizontal linkages establishing club Union to increase the social influence of the former club and promoting the sports undertakings.

\section{CONCLUSIONS}

Social capital is an intangible asset of nonprofit sports clubs affecting the club's funding sources. Accumulation of social capital increases the amount of capital funding to ensure sufficient funds for the development of public service of the sports clubs. Therefore, nonprofit sports clubs should focus on the accumulation and development of social capital, so that the clubs can contribute to the long-term development of sports.

\section{REFERENCES}

[1] Yoshio KAKIZAKI and Hidekazu TSUJI, "A Decentralized Attribute Management Method and its Implementation", IJIPM, Vol. 3, No. 1, pp. $61 \sim 69,2012$

[2] Hamid Turab Mirza, Ling Chen, Gencai Chen , "Practicability of Dataspace Systems", JDCTA, Vol. 4, No. 3, pp. $233 \sim 243$, 2010

[3] Lei Chen, Mingran Deng, "Study on Algorithm of Statistics for Bolts Information of Steel Bridge and Iron Tower Based on Assembly Feature", AISS, Vol. 3, No. 10, pp. $1 \sim 11,2011$

[4] Xiang LIU †, Jinhai SUN, Yaping HE, Yimin LIU, Li CAO, "Overview of Virtual Reality Apply to Sports", JCIT, Vol. 6, No. 12, pp. $1 \sim \sim$ 7, 2011

[5] FANG Lu. Application of the Internet of Things Technology in the Museum Service[J]. Bulletin of Science and Technolog, 2013,3(28):166-168.

[6] LIN Wei,YUAN Bing-cheng,ZHANG Jian. Signal detection algorithm of underwater detection based on band-pass filter and BP neural network[J]. Journal of Naval University of Engineering, 2012,3:5-6 